\title{
Effects of suboptimal temperatures on larval and juvenile development and otolith morphology in three freshwater fishes: implications for cold water pollution in rivers
}

\author{
Laura E. Michie $(\mathbb{D} \cdot$ Jason D. Thiem $(\mathbb{D} \cdot$ Jordan A. Facey • \\ Craig A. Boys $\mathbb{D}$ - David A. Crook $(\mathbb{D} \cdot$ Simon M. Mitrovic $\mathbb{C}$
}

Received: 25 June 2020 / Accepted: 25 October 2020

(C) Springer Nature B.V. 2020

\begin{abstract}
Temperature is a key determinant that governs fish survival, reproduction, growth and metabolism. In freshwater ecosystems, anthropogenic influences have resulted in acute and prolonged temperature changes which lead to lethal and sub-lethal impacts on the biota that occupy these environments. We assessed the effects of temperature on somatic and otolith growth and development of three species of native Australian freshwater fish (silver perch Bidyanus bidyanus, trout cod Maccullochella macquariensis and golden perch Macquaria ambigua) to simulate how thermal pollution from the release of unseasonably cold water from thermally stratified dams in Australian freshwater
\end{abstract}

Supplementary Information The online version contains supplementary material available at https://doi.org/10.1007 /s10641-020-01041-z.

L. E. Michie $(\bowtie) \cdot J$. A. Facey $\cdot$ S. M. Mitrovic

School of Life Sciences, University of Technology Sydney, PO

Box 123, Broadway, New South Wales 2007, Australia

e-mail: Laura.Michie@uts.edu.au

J. D. Thiem

NSW Department of Primary Industries, Narrandera Fisheries

Centre, PO Box 182, Narrandera, New South Wales 2700,

Australia

C. A. Boys

NSW Department of Primary Industries, Port Stephens Fisheries Centre, Taylors Beach Road, Taylors Beach, New South Wales 2316, Australia

\section{A. Crook}

Centre for Freshwater Ecosystems, La Trobe University, McCoy Street, Albury-Wodonga, Victoria 3690, Australia ecosystems may impact fish at critical life-history stages. Fish (31 days post-hatch) were exposed to four temperature treatments $\left(13,16,20,24^{\circ} \mathrm{C}\right)$ for 30 days. Low temperatures resulted in reduced somatic growth, with no growth observed in silver perch and golden perch held at $13^{\circ} \mathrm{C}$ over 30 days. Somatic growth was highest at the upper temperature of $24^{\circ} \mathrm{C}$. Morphological assessment of fish size reiterated that low water temperatures resulted in reduced body size, particularly in terms of body width and head size. Low temperatures were associated with reduced otolith growth in all species, however a somatic-otolith size relationship was maintained for all species in measures of otolith weight, area, length and perimeter. The sub-lethal impacts observed in our study are likely to manifest at the population level through a reduced capacity of larvae and juveniles to avoid size-dependent predation, a narrower range of prey sources due to extended gape-limited feeding and, ultimately, poorer survival and recruitment.

Keywords Fish · Freshwater - Growth - Otolith · Temperature $\cdot$ Thermal pollution

\section{Introduction}

Temperature is an important regulator of the biological processes of aquatic organisms (Brett 1971). As ectotherms, fish depend on temperature as a determinant of metabolism, spawning and survival and are adapted to specific temperature ranges (Brett 1971; Jobling 1995; Beitinger et al. 2000). The optimal thermal range of fish 
is determined by genetic histories and the thermal histories of the ecosystems they inhabit, as such thermal tolerance can vary widely between species but can also vary intra-specifically (Beitinger et al. 2000; Gunderson and Stillman 2015; Comte and Olden 2017). Within these ranges, metabolic functions such as feed utilization, growth, reproduction and swimming ability are enhanced (Jobling 1997; Beitinger et al. 2000). Optimal temperature ranges may also vary between life-history stages within species, where efficacy of metabolic functioning is necessary to support periods of rapid growth and development or reproduction (Morita et al. 2010). Maintaining optimal environmental thermal conditions is essential for fish at early life history stages when developmental changes and rapid growth are occurring and sensitivity to suboptimal thermal conditions is high (Sogard 1997).

Growth and body size is a major determinant for survival in fish, particularly during larval and juvenile life-history stages (Childs and Clarkson 1996; Sogard 1997). Reduced body size increases predation risk (Rice et al. 1987), size-dependent competition (Fausch and White 1986) and susceptibility to temperature extremes and changes (Johnson and Evans 1990; Johnson and Evans 1996; Clarkson and Childs 2000). Temperature can affect growth potential in fish as it drives metabolic functioning, which is essential for optimal feeding efficiency, ensuring that surplus energy is attained through food intake and can be converted into somatic growth (Kitchell et al. 1977; Buentello et al. 2000). Temperature-driven reductions in growth rate and/or body size in larval and juvenile fish increases their vulnerability to numerous stressors and ultimately affects fitness and survival.

Another potentially important effect of temperature on fish is its influence on the development of otoliths (fish ear stones). Otoliths are calcified structures that develop incrementally, forming annual and daily increments that are frequently used for ageing and backcalculating the growth histories of fish (Pannella 1971; Gauldie and Nelson 1990; Morrongiello et al. 2012) and for assessing life history events and past environmental conditions of individuals and populations of fish (Campana and Neilson 1985; Jones 1992; Campana 1999; Sponaugle 2010). Otolith growth is strongly linked to somatic growth (Gagliano and McCormick 2004; Starrs et al. 2013), however under certain conditions otolith growth can decouple from somatic growth (Barber and Jenkins 2001; Folkvord et al. 2004;
Baumann et al. 2005; Tonkin et al. 2008a; Tonkin et al. 2008b). This can complicate, or even invalidate, the use of these structures in biochronological studies and as proxies for back-calculating growth histories (Morrison et al. 2019). Understanding how otolith growth and its relationship with somatic growth is affected by thermal stress is essential for the application of otolith biochronological analyses in fisheries science.

Suboptimal thermal conditions in river ecosystems can originate from numerous sources causing either a warming or cooling of the thermal regime. Warm water pollution can be caused by industrial effluents, urban run-off and global warming (Verones et al. 2010; Van Vliet et al. 2013), whereas cold water pollution can be caused by large dams that release hypolimnetic water during periods of thermal stratification (Weber et al. 2017). Suboptimal thermal conditions have been identified as a contributing factor in historical reductions in native fish populations in freshwater, estuarine and marine ecosystems; therefore managing various sources of thermal pollution is essential in improving native fish stocks in many parts of the world (Clarkson and Childs 2000; Koehn 2001; Roessig et al. 2004; Lugg and Copeland 2014).

In Australian freshwater ecosystems, thermal reductions from large dam releases can reduce river temperature by as much as $16^{\circ} \mathrm{C}$ (Lugg and Copeland 2014), with thermal suppressions persisting for up to $300 \mathrm{~km}$ downstream (Burton 2000; Lugg and Copeland 2014). This 'cold water pollution' has been documented widely in Australian rivers and has had a strong, adverse impact on native fish populations (Burton 2000; Todd et al. 2005; Sherman et al. 2007; Lugg and Copeland 2014; Gray et al. 2019; Michie et al. 2020).

The aim of this study was to determine the effect of temperature on somatic growth and otolith development in early life-history stages of three species of Australian freshwater fish that occupy rivers impacted by coldwater pollution; silver perch (Bidyanus bidyanus), trout cod (Maccullochella macquariensis) and golden perch (Macquaria ambigua). We subjected individuals of each species to a range of water temperatures that were representative of Murray-Darling Basin rivers affected by cold water pollution. Cold water pollution is extensive within the Murray-Darling Basin, the native habitat of the three test species. Experimental temperatures were selected based on a 20-year analysis of water temperatures downstream of Burrendong Dam on the Macquarie River (Michie et al. 2020), and also 
encompass temperatures observed in a number of rivers across the Murray-Darling Basin (Burton 2000; Todd et al. 2005; Sherman et al. 2007; Lugg and Copeland 2014; Gray et al. 2019). We anticipated that cooler water temperatures may reduce growth potential in the species of fish tested due to the influence of temperature on biological and metabolic processes. Further, we predicted that the threatened species being tested (silver perch and trout cod) may be more sensitive to thermal pollution given historic range reductions and population declines in heavily regulated systems. The results of our study are discussed with regard to their relevance to the management of fish populations in regions affected by thermal pollution.

\section{Methods}

\section{Experimental set-up}

Silver perch, trout cod and golden perch were acquired 31 days post-hatch (dph) from the Department of Primary Industries (DPI) Narrandera Fisheries Centre hatchery in New South Wales, Australia. Trials were run sequentially due to the availability of the fish being affected by the specific timing of breeding for each species. Individuals for each species were selected from mixed breeding pairs. Fish were transferred to experimental aquaria containing bore water of $20^{\circ} \mathrm{C}$, matching the hatchery water conditions. The experimental set-up was within a light and temperature-controlled room at the Narrandera Fisheries Centre; room temperature was maintained at approximately $25{ }^{\circ} \mathrm{C}$ and light was sustained on a 12:12 cycle. Four replicate aquaria (3 L) were maintained for each temperature treatment, they were submersed in large water baths $(70 \mathrm{~L})$ which were temperature controlled by water chillers (HC300A Hailea, China) to maintain constant temperature. Each replicate was fitted with a temperature logger (HOBO Pendant TM, Onset, U.S.A., accuracy $\pm 0.53{ }^{\circ} \mathrm{C}$ ) and an aeration system. Each experiment was conducted over 30 days, which included acclimation to the experimental temperatures $(13,16,20$ and $24^{\circ} \mathrm{C}$ ) over a maximum period of 4 days. Throughout the experiment, the temperature loggers within each replicate tank monitored temperature at 15-min intervals. Measurements of temperature, dissolved oxygen, $\mathrm{pH}$ and conductivity were taken daily. Fish were fed three times daily to satiation in accordance with hatchery procedures on a diet of live Artemia (Artemia franciscana), which were hatched onsite. Tanks were cleaned daily, with an approximate $30 \%$ water exchange and any uneaten food removed.

Sampling procedure

Approximately 40 fish per species were removed at the beginning of the trial (day zero) to attain initial size data. Remaining fish were exposed to the temperature treatments for 30 days (approximately 15 per replicate aquaria) and were sampled at the end of the trial. At the cessation of experiments, all remaining fish were euthanized using a benzocaine overdose of $100 \mathrm{mg} \mathrm{L}^{-1}$. Following euthanasia, photographs of each fish were taken under a dissecting microscope and camera (MC120 HD, Leica, Germany) for morphological assessment. The fish were photographed laterally in a head-to-left orientation, on a stage micrometer with a $0.01 \mathrm{~mm}$ scale. After photographs were taken, measurements of weight, total length, and maximum vertical mouth gape were taken with a digital Vernier calliper. Sagittal otolith pairs were removed from the fish under a dissecting microscope, washed in clean water and stored in black well microplates. Otolith dry weight $(\mu \mathrm{g})$ was measured from one otolith from each fish. The otoliths were then photographed in high contrast under a dissecting microscope (MZ 16, Leica, Germany) and camera (Infinity 1, Lumenera, Canada) on a stage micrometre with a $0.01 \mathrm{~mm}$ scale; they were orientated with the rostrum to the left of the image.

Data analysis of fish growth

Measurements of fish weight, length and mouth gape were calculated as proportional change from the average size fish at day zero for each species. Specific growth rate (SGR) was calculated according to Jobling (1983) using the average initial start weight $\left(w_{i}\right)$, the final weight $\left(w_{t}\right)$ and the duration of the exposure $(t)$. SGR was represented as a percent increase in body mass per day.

$S G R=\frac{\ln \left(w_{t}\right)-\ln \left(w_{i}\right)}{t} \times 100$

To determine differences in all measures of fish growth between initial and final measurements, and 
between temperature treatments at the finish of the experiment, we conducted parametric analysis of variance (ANOVA). Where parametric assumptions were not met, a log transformation of the data was performed. Significant differences among treatments were determined using a Tukey's post hoc test. All statistical analyses were conducted in $\mathrm{R}$ version 3.5.1 (R Core Team 2019) with a significance level of $\alpha<0.05$.

Image-J software (Schindelin et al. 2012) was used to take morphometric measurements of each individual fish based on a truss network protocol which measured 21 lengths between 10 homologous anatomical landmarks (Fig. 1). Anatomical landmarks refer to (1) the anterior tip of the snout on the upper jaw, (2) the origin of the scaled nape, (3) the origin of the pelvic fin, (4) the origin of the spinous dorsal fin, (5) the origin of the anal fin, (6) the origin of the soft dorsal fin, (7) the cessation of the anal fin, (8) the cessation of the soft dorsal fin, (9) the ventral origin of the caudal fin and (10) the dorsal origin of the caudal fin. Principal component analysis of the morphometric measurements was undertaken using the vegan package in $\mathrm{R}$ (Oksanen et al. 2010). The four measures that contributed towards the highest variation in size between treatments $(>80 \%)$ were identified and used as descriptors of the first principal component.

Data analysis of otolith growth and development

Assessment of otolith growth and development was conducted in R (R Core Team 2019) using the R packages ShapeR (Libungan and Pálsson 2015a) and vegan (Oksanen et al. 2010), with methods as described by Libungan and Pálsson (2015b). Otolith outlines were extracted from digital otolith images by transforming the images to grey-scale and designating a threshold pixel value to distinguish the white otolith from the black background. Wavelet shape coefficients were extracted from the otolith outline by measuring radii from the otolith centroid to the otolith outline, the Wavelet

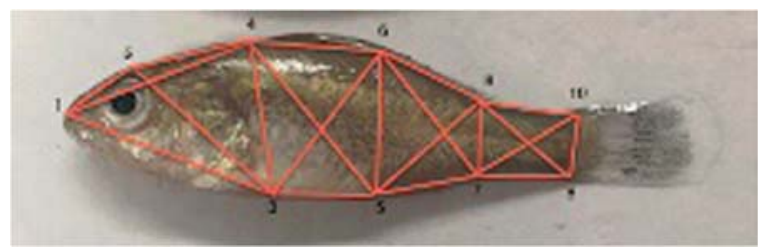

Fig. 1 Location of 10 anatomical landmarks and connected truss network measured on each fish for morphometric analysis. Pictured: golden perch (Macquaria ambigua) method of analysis was selected due to its usefulness in detecting shape differences in specific regions of the otolith. Measurements of otolith area, otolith length and otolith perimeter were then extracted for each otolith with pixel calibrations applied for images taken at different magnifications.

To conduct analysis of otolith shape, the size of the otolith was normalized by dividing the otolith coordinates by the square root of the otolith area. Examination of variation in otolith shape between each treatment was conducted by plotting mean otolith shape from the previously extracted otolith outlines and using the normalized co-ordinates to remove size-bias. Wavelet coefficients were adjusted for fish length before the mean and standard deviation of all combined coefficients and the proportion of variance between groups (intraclass correlation) was plotted against the angle of the measured otolith outline (in degrees, based on polar coordinates) to determine the regions of the otolith driving variation in shape between groups.

To determine if there was variation in otolith development between temperature treatments for measures of otolith weight, area, length and perimeter, group means were compared using parametric analysis of variance (ANOVA), with log transformation applied where data did not meet test assumptions. Statistical analysis of shape was conducted by applying Canonical Analysis of Principal coordinates (CAP) on the length standardized Wavelet coefficients and running an ANOVA-like permutation test using 1000 permutations to evaluate differences between the temperature treatments for each species (Libungan and Pálsson 2015b).

\section{Results}

Fish growth

Temperature had a significant effect on growth in all three species; silver perch (SP), trout cod (TC) and golden perch (GP) (Figs. 2 and 3). Temperature affected fish in terms of changes in total length (SP: $F_{4,272}=$ $416.2, p<0.001$, TC: $F_{4,143}=473.8, p<0.001, \mathrm{GP}: F_{4}$, $254=135.5, p<0.001)$ and weight (SP: $F_{4,272}=305.6$, $p<0.001$, TC: $F_{4,143}=278.1, p<0.001$, GP: $F_{4,254}=$ $151.7, p<0.001)$. Growth in all species was highest at the maximum temperature treatment of $24{ }^{\circ} \mathrm{C}$ and lowest at the minimum temperature of $13{ }^{\circ} \mathrm{C}$. In all species there was a significant reduction in the size of fish 
Fig. 2 Growth in length and weight of silver perch, trout cod and golden perch after exposure to a range of water temperatures. Growth is measured as the proportional (\%) change in size from sample fish measured on day zero after 30 days exposure to water temperatures of 13, 16, 20 and $24{ }^{\circ} \mathrm{C}$. Error bars are calculated as standard error of the mean

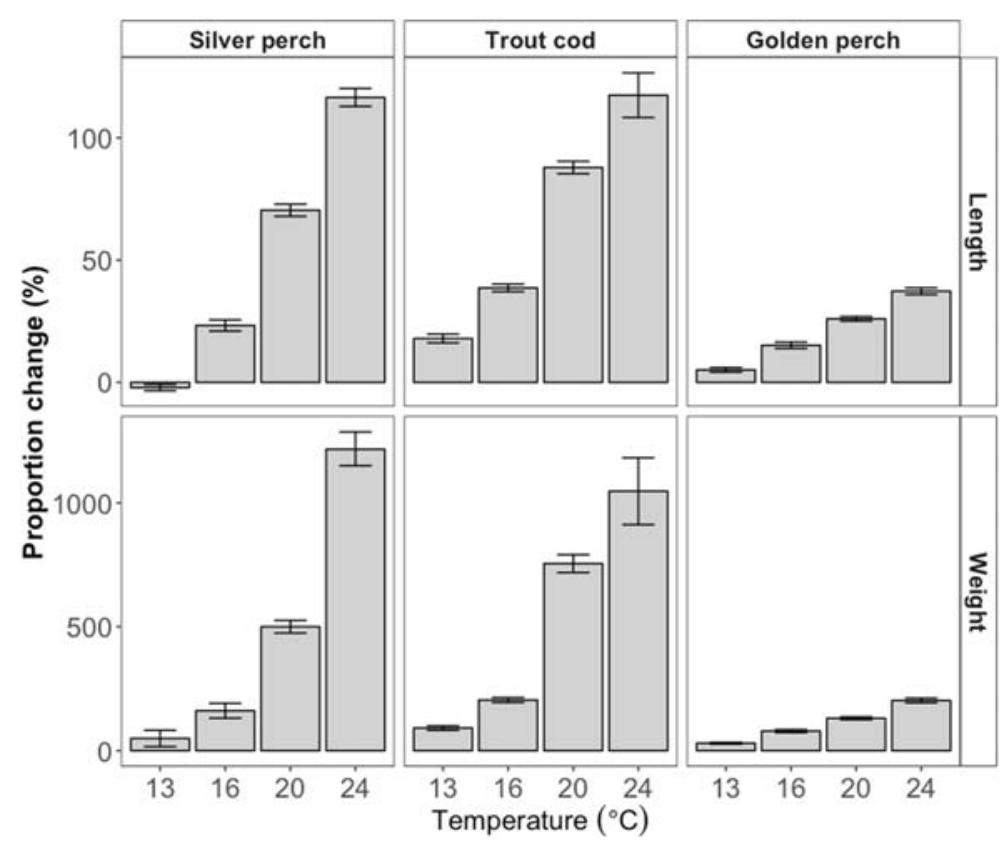

(length and weight) with each incremental reduction in temperature. There was no significant difference between the somatic growth of silver perch and golden perch when held at $13{ }^{\circ} \mathrm{C}$ for 30 days compared with day zero.

Temperature affected mouth gape in silver perch $\left(F_{4,272}=243.9, p<0.001\right)$ trout $\operatorname{cod}\left(F_{4,143}=104.5\right.$, $p<0.001)$ and golden perch $\left(F_{4}, 254=51.58\right.$, $p<0.001$ ) (Fig. 4). In all species mouth gape was smaller in fish exposed to reduced water temperatures. No significant changes in mouth gape were found between silver perch held at $13{ }^{\circ} \mathrm{C}$ and fish measured at day zero. Similarly, there was no statistical difference between golden perch held at $13{ }^{\circ} \mathrm{C}$ and $16{ }^{\circ} \mathrm{C}$ and fish measured at day zero. A strong linear relationship was maintained between fish length (LT) and mouth gape (MG) for all

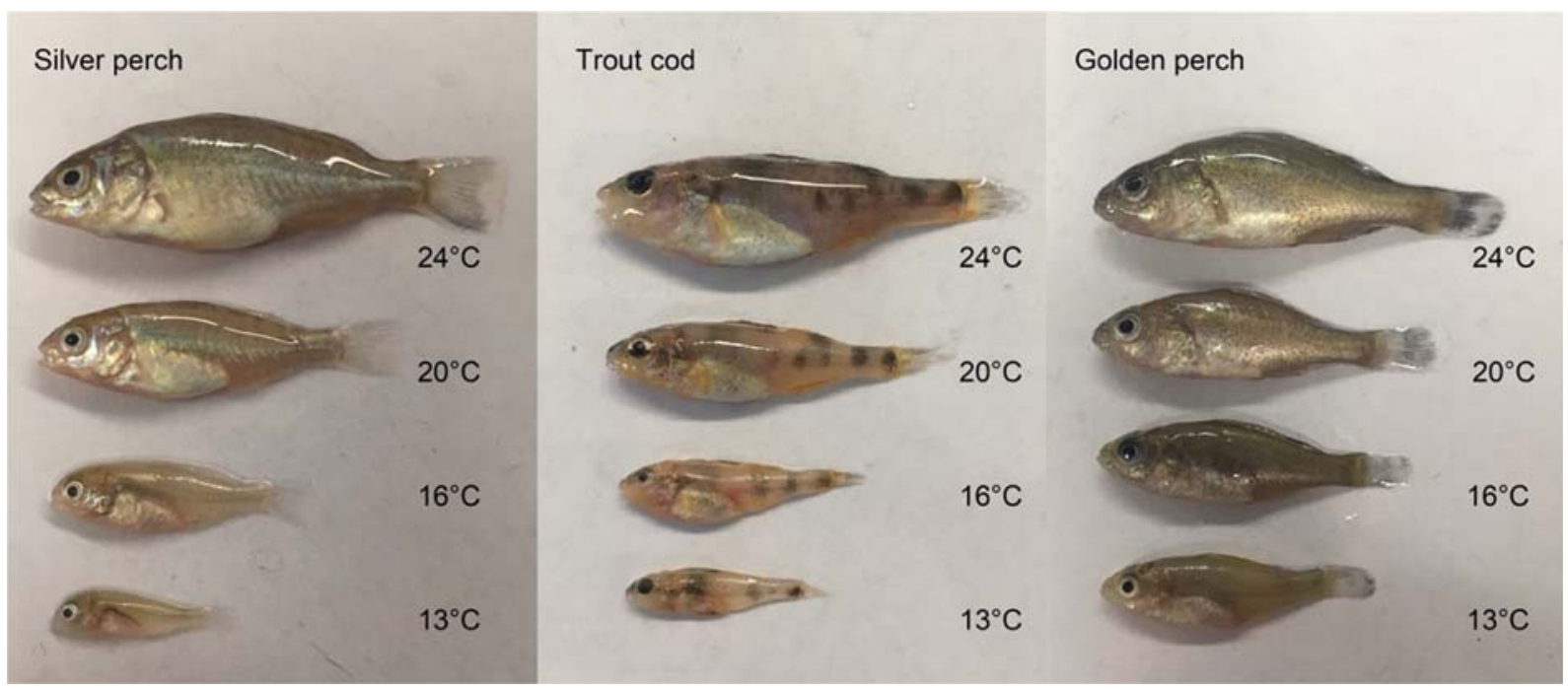

Fig. 3 Photographic comparison of silver perch, trout cod and golden perch after exposure to a range of water temperatures. Fish were exposed to water temperatures of $13,16,20$ and $24^{\circ} \mathrm{C}$ for
30 days. The fish selected for photographs were similar in length to the calculated mean for each treatment 
Fig. 4 The effect of water temperature on the mouth gape (MG) of three species of fish in relation to total length (LT). Each data point represents an individual fish, measured on day zero of the experiment (black markers) or after 30 days of exposure to water temperatures of $13{ }^{\circ} \mathrm{C}, 16^{\circ} \mathrm{C}$, $20^{\circ} \mathrm{C}$ and $24^{\circ} \mathrm{C}$ (colour markers). Confidence intervals $(95 \%)$ are indicated in grey

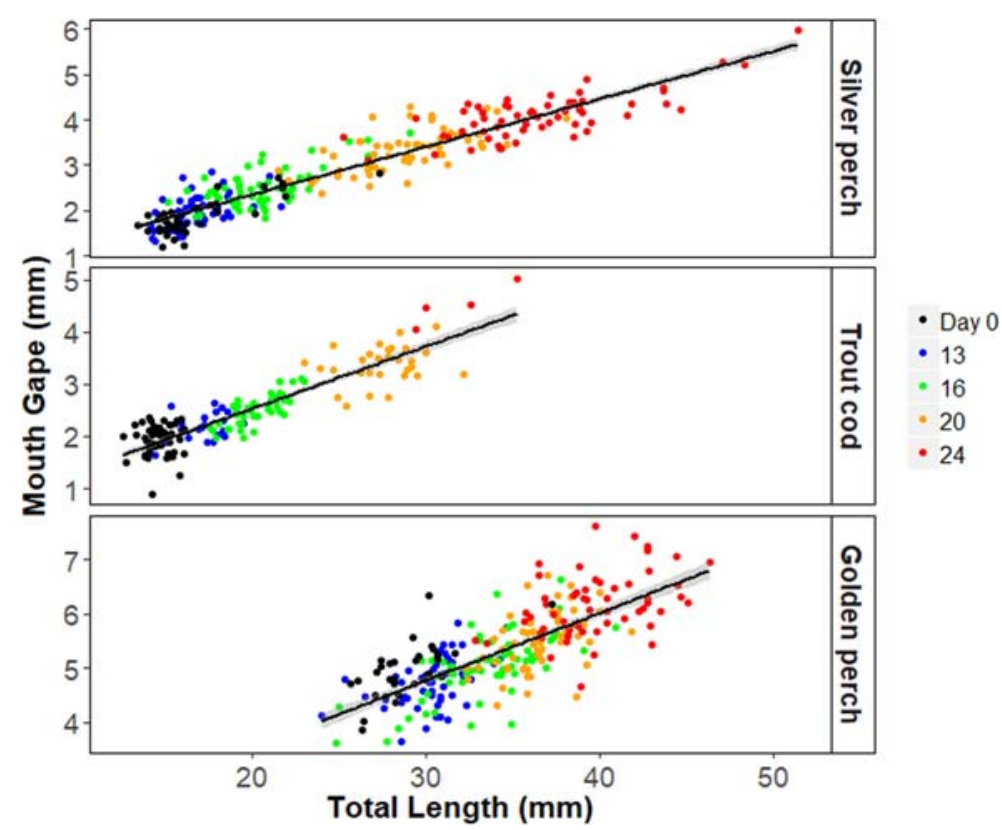

species (SP: $\mathrm{MG}=0.106^{*} \mathrm{LT}+0.235$; adj $\mathrm{R}^{2}=0.88$, TC: $\mathrm{MG}=0.120^{*} \mathrm{LT}+0.138 ;$ adj $\mathrm{R}^{2}=0.82, \mathrm{GP}: \mathrm{MG}=$ $0.125 * \mathrm{LT}+1.025$; adj $\mathrm{R}^{2}=0.57$ ).

Temperature affected specific growth rate (SGR) in silver perch $\left(F_{3,233}=317.3, p<0.001\right)$, trout $\operatorname{cod}\left(F_{3}\right.$, $\left.{ }_{94}=232.9, p<0.001\right)$ and golden perch $\left(F_{3,225}=126.6\right.$, $p<0.001)$, although the effect was lower in golden perch (Fig. 5). SGR was minimized when water temperatures were reduced. SGR varied between all treatments in all species except for silver perch exposed to $13{ }^{\circ} \mathrm{C}$ and $16{ }^{\circ} \mathrm{C}$ water temperatures. SGR reduced incrementally as temperature was reduced.

Temperature also affected growth as measured using a combination of morphometric traits (Fig. 6). Traits that contributed to the largest variation in size between treatments originated from measures 3, 6, 9 and 11 in all species, and these contributed $>80 \%$ of the variation in size. These measures reflect size of the head and body
Fig. 5 Specific growth rate (SGR) of silver perch, trout cod and golden perch after exposure to a range of water temperatures. SGR is calculated as the percentage increase in body weight measured daily as calculated after 30 days exposure to water temperatures of $13,16,20$ and $24{ }^{\circ} \mathrm{C}$. Error bars are calculated as standard error of the mean

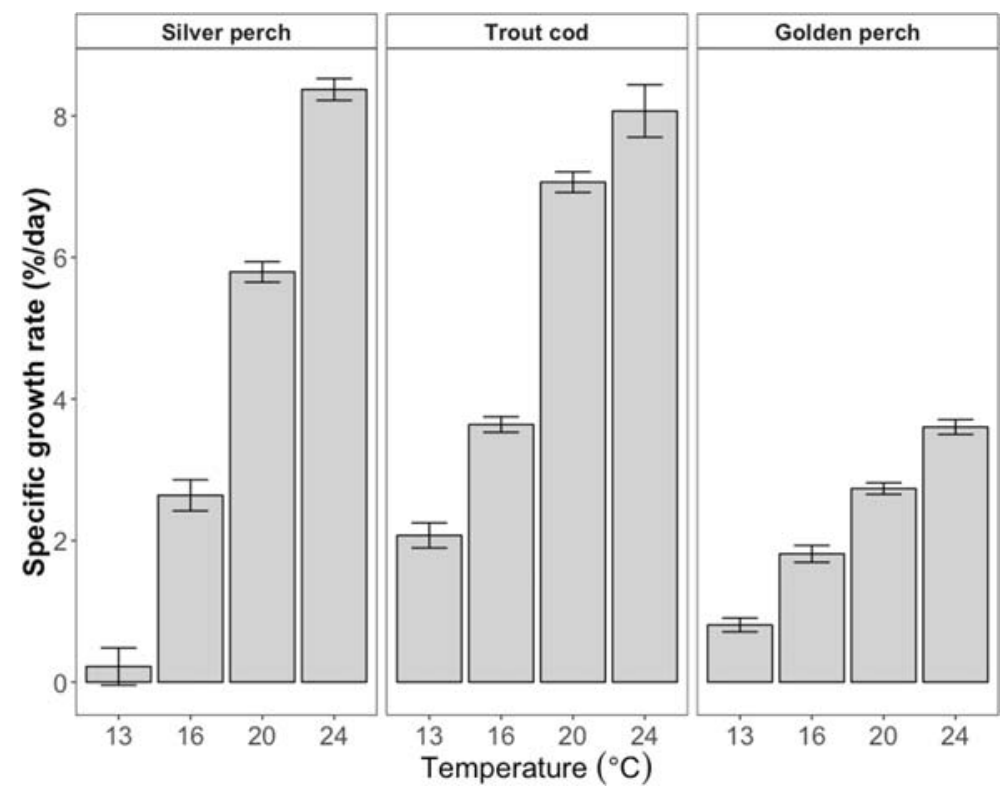


Fig. 6 Visualization of principal components analysis (PCA) indicating variation in the morphometric truss body network measurements of silver perch, trout cod and golden perch. The PCA compares groups after 30 days of exposure to water temperatures of $13,16,20$ and $24{ }^{\circ} \mathrm{C}$ to fish as measured on day zero of the experiment
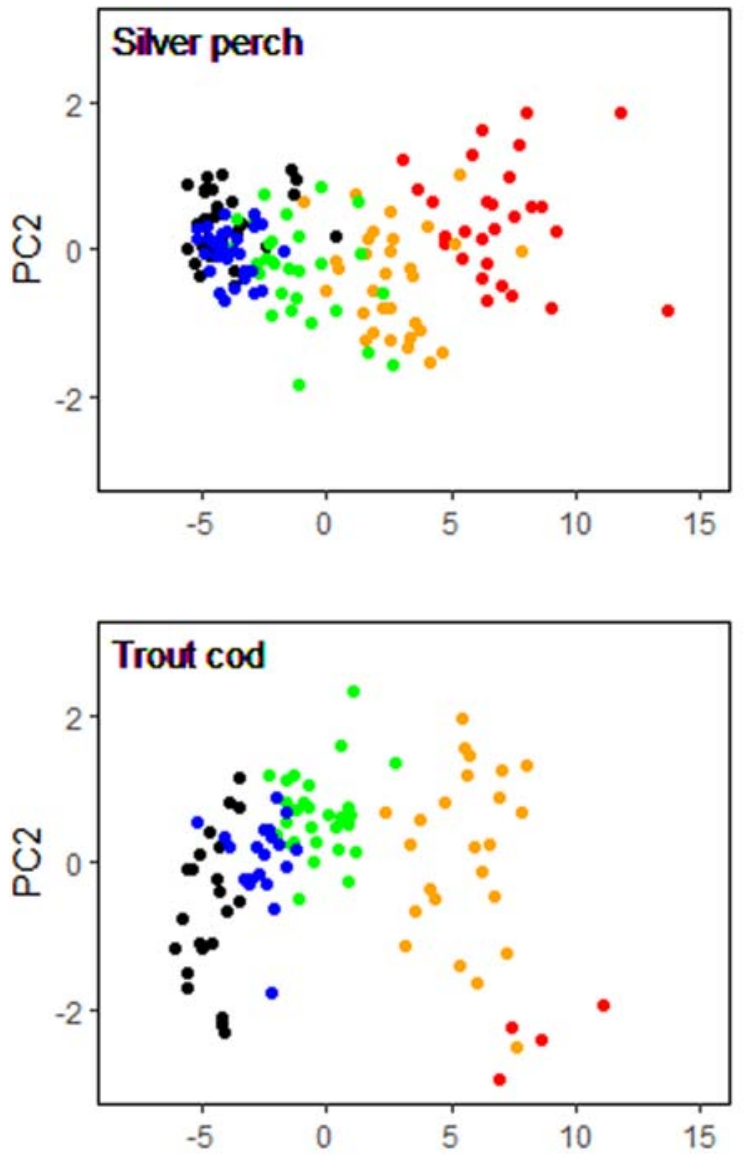

- Day 0

- 13

- 16

- 20

- 24

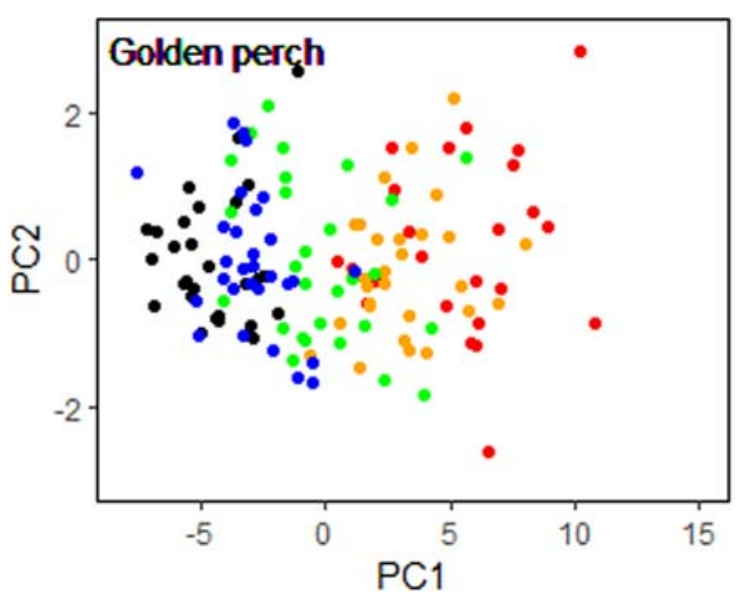

width; with measure 3 being from the anterior tip of the snout on the upper jaw to the origin of the spinous dorsal fin, measure six being from the origin of the pelvic fin to the origin of the spinous dorsal fin, measure nine being from the origin of the spinous dorsal fin to the origin of the anal fin and measure 11 being the from the origin of the anal fin to the origin of the soft dorsal fin (Fig. 1). There was greater variation in size between treatments observed in silver perch and trout cod than there was in golden perch (Fig. 2). 


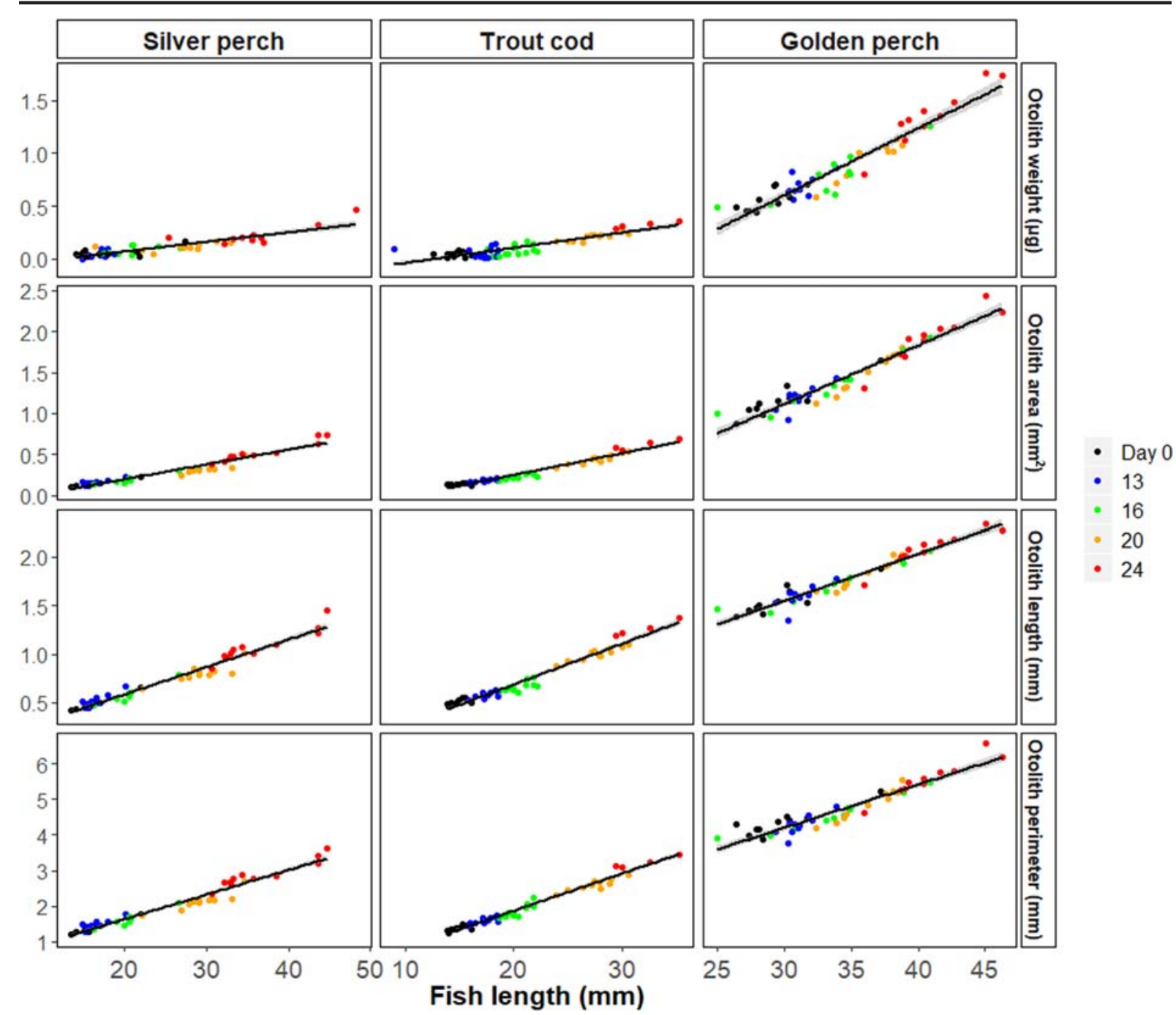

Fig. 7 The effect of water temperature on otolith weight $(\mu \mathrm{g})$, otolith area $\left(\mathrm{mm}^{2}\right)$, otolith length $(\mathrm{mm})$ and otolith perimeter $(\mathrm{mm})$ of silver perch, trout cod and golden perch in relation to total length (LT). Each data point represents an individual fish, measured on day zero of the experiment (black markers) or after 30 days of exposure to water temperatures of $13,16,20$ and $24{ }^{\circ} \mathrm{C}$ (colour markers). Confidence intervals (95\%) indicated in grey

measures of otolith weight, otolith area, otolith length, and otolith perimeter.

Otolith development

Otolith shape varied between fish held at different temperatures in silver perch $\left(\mathrm{F}_{1}=8.527, p=0.002\right)$, trout $\operatorname{cod}\left(\mathrm{F}_{1}=12.168, p=0.001\right)$ and golden perch $\left(\mathrm{F}_{1}=\right.$ 5.761, $\mathrm{p}=0.001$ ) (Fig. 8). In silver perch, the highest variation between treatments in the Wavelet coefficients 
Table 1 Summary statistics of one-way ANOVA for differences between temperature treatments within measures of otolith weight $(\mathrm{OW})$, otolith area $(\mathrm{OA})$, otolith length $(\mathrm{OL})$ and otolith perimeter

\begin{tabular}{|c|c|c|c|c|c|}
\hline & Measure & F value & $P$ value & Linear regression & Adj. $R^{2}$ \\
\hline \multirow[t]{4}{*}{ Silver perch } & OW & $F_{4,43}=17.46$ & $p<0.001$ & $\mathrm{OW}=0.009 * \mathrm{LT}-0.111$ & 0.770 \\
\hline & $\mathrm{OA}$ & $F_{4,47}=72.72$ & $p<0.001$ & $\mathrm{OA}=0.018 * \mathrm{LT}-0.162$ & 0.937 \\
\hline & $\mathrm{OL}$ & $F_{4,48}=67.78$ & $p<0.001$ & $\mathrm{OL}=0.028 * \mathrm{LT}+0.027$ & 0.956 \\
\hline & $\mathrm{OP}$ & $F_{4,47}=70.49$ & $p<0.001$ & $\mathrm{OP}=0.069 * \mathrm{LT}+0.246$ & 0.956 \\
\hline \multirow[t]{4}{*}{ Trout cod } & OW & $F_{4,52}=68.46$ & $p<0.001$ & $\mathrm{OW}=0.014 * \mathrm{LT}-0.182$ & 0.787 \\
\hline & $\mathrm{OA}$ & $F_{4,42}=200.5$ & $p<0.001$ & $\mathrm{OA}=0.0265^{*} \mathrm{LT}-0.281$ & 0.958 \\
\hline & $\mathrm{OL}$ & $F_{4,41}=249.8$ & $p<0.001$ & $\mathrm{OL}=0.042 * \mathrm{LT}-0.152$ & 0.962 \\
\hline & $\mathrm{OP}$ & $F_{4,41}=164.3$ & $p<0.001$ & $\mathrm{OP}=0.105^{*} \mathrm{LT}-0.221$ & 0.973 \\
\hline \multirow[t]{4}{*}{ Golden perch } & OW & $F_{4,44}=24.71$ & $p<0.001$ & $\mathrm{OW}=0.064 * \mathrm{LT}-1.309$ & 0.906 \\
\hline & $\mathrm{OA}$ & $F_{4,45}=15.26$ & $p<0.001$ & $\mathrm{OA}=0.0265^{*} \mathrm{LT}-0.281$ & 0.958 \\
\hline & $\mathrm{OL}$ & $F_{4,45}=18.46$ & $p<0.001$ & $\mathrm{OL}=0.048^{*} \mathrm{LT}+0.097$ & 0.929 \\
\hline & OP & $F_{4,45}=15.08$ & $p<0.001$ & $\mathrm{OP}=0.122 * \mathrm{LT}+0.537$ & 0.897 \\
\hline
\end{tabular}

(OP). Linear regression model is included for the comparison of fish length (LT) against otolith measures irrespective of treatment group
(ICC) existed at angles $30-80^{\circ}, 180-250^{\circ}$ and $300^{\circ}$ of the otolith outline indicating development towards a longer more rectangular otolith with a more developed rostrum at warmer temperature treatments. Trout cod exhibited the greatest variation in otolith shape in regions $140-240^{\circ}$ and $350-40^{\circ}$ of the otolith outline, again indicating rectangular development and a more developed rostrum at the warmer temperature treatments. Variation in shape in golden perch was less distinct; variation was highest at angles $260-10^{\circ}$.

\section{Discussion}

Slow somatic growth and reduced body size of fish during larval and juvenile life-history stages is strongly linked to mortality and delays in reaching sexual maturity (Sogard 1997). As such, environmental conditions that reduce growth potential of early life stages may have significant deleterious effects on the productivity of fish populations. In this study we demonstrated that low water temperatures reduced somatic growth in the early-life history stages of three species of Australian freshwater fish. This is significant within the context of widespread cold-water pollution downstream of thermally stratified dams with bottom-level offtakes. For example, in Australia large dams located in temperate regions have been documented to reduce water temperatures in downstream rivers by as much as $16^{\circ} \mathrm{C}$ with water temperatures as low as $12-13{ }^{\circ} \mathrm{C}$ being reported (Burton 2000; Lugg and Copeland 2014; Michie et al. 2020). We demonstrate that these temperatures would have a profound effect on individual fish growth rates and manifest significant negative impacts upon populations. All species experienced limited growth when held at $13{ }^{\circ} \mathrm{C}$, with silver perch and golden perch experiencing no growth at this temperature over 30 days. In their native range within the Murray-Darling Basin, approximately $2000 \mathrm{~km}$ of collective river length can be affected by reduced water temperatures originating from large reservoirs (NSW-CWPIG 2012). Our study highlights the need for effective mitigation of thermal pollution in this region.

In a number of species, delayed ontogenetic development occurs at lower water temperatures, extending the duration of larval stages and increasing mortality risk (Clarkson and Childs 2000; Green and Fisher 2004; Kitchell et al. 1977). A number of MurrayDarling Basin native fish species have demonstrated reduced growth when exposed to suboptimal water temperatures; these species include juvenile freshwater catfish (Tandanus tandanus), Murray cod (Maccullochella peelii) (Ryan et al. 2003), silver perch (Astles et al. 2003) and spangled perch (Leiopotherapon unicolor) (Gehrke 1988). Juvenile silver perch exposed to natural thermal regimes were roughly twice the weight of fish 

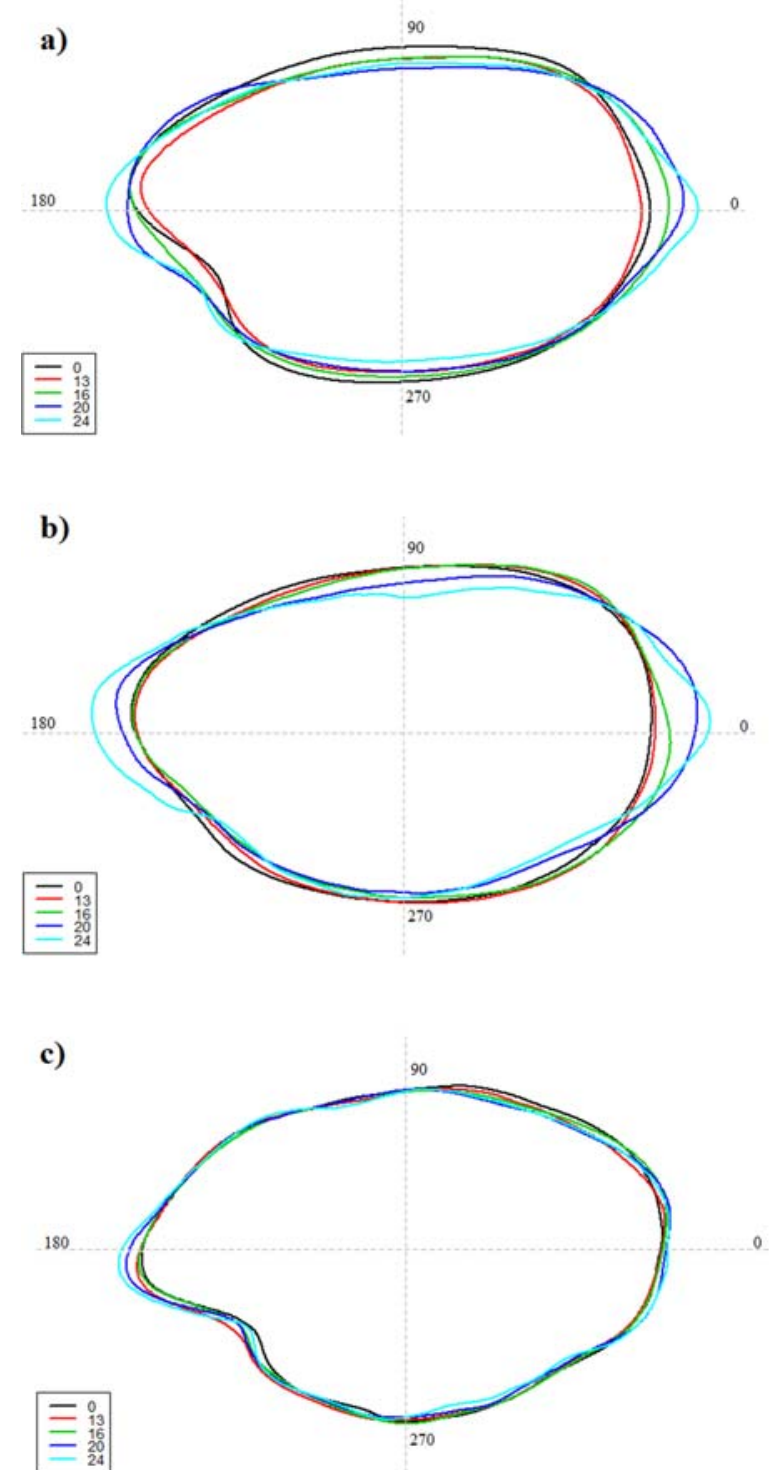

Fig. 8 Average otolith shape based on Wavelet analysis of a) silver perch, b) trout cod and c) golden perch. Otoliths were assessed prior to exposure ( 0 ) and after 30 days exposure to water temperatures of $13,16,20$ and $24{ }^{\circ} \mathrm{C}$. Day 0 is represented in black. Numbers represent the angles in degrees $\left({ }^{0}\right)$ based on polar coordinates, with the centroid being indicated by the centre of the cross (dashed lines)

exposed to thermal conditions of a river affected by cold water pollution ( $11^{\circ} \mathrm{C}$ difference) (Astles et al. 2003). Our analysis of silver perch indicates the increased sensitivity of this younger age group to suboptimal thermal regimes; at similar temperature exposures over a similar time frame, we demonstrated that silver perch weight was approximately 10 times higher when exposed to the simulated natural thermal regimes compared to temperatures that can occur in a thermally polluted river. Temperature plays a similar role in the growth performance of fish throughout the world, particularly in early life-history stages. Suboptimal temperatures have caused reduced somatic growth in a number of species including greater amberjack (Seriola dupmerili) (Fernández-Montero et al. 2018), Atlantic cod (Gadus morhua) (Pérez-Casanova et al. 2009), humpback chub (Gila cypha), Colorado squawfish (Ptychocheilus lucius) (Clarkson and Childs 2000), yellowtail kingfish (Seriola lalandi) (Abbink et al. 2012), Atlantic halibut (Hippoglossus hippoglossus) (Jonassen et al. 1999) and turbot (Scophthalmus maximus) (Imsland et al. 1996).

Suboptimal water temperatures in aquatic ecosystems pose a significant threat to the viability of fish species as reduced body size in fish can increase their vulnerability to a number of stressors and may ultimately affect fitness and survival. Swimming ability in fish is dependent on both body size and water temperature (Wolter and Arlinghaus 2003). Body size is positively correlated with swimming ability (Fisher et al. 2005; Ojanguren and Brana 2003), particularly in terms of sustained, prolonged and maximum swimming speeds (Domenici 2001). Predator-prey interactions are directly linked to swimming speed limits and endurance in fish; reductions in the swimming performance of larval fish is likely to affect survival and growth potential of fish, through increasing predation risk and limiting their ability to capture prey (Domenici and Blake 1997; Videler and Wardle 1991; Wolter and Arlinghaus 2003). Independent of size, swimming ability in fish is often reduced at suboptimal temperatures. In golden perch, fast-start performance was considerably reduced at temperatures below $15.5{ }^{\circ} \mathrm{C}$ (Lyon et al. 2008) and sprint and sustained swimming performance was reduced in Macquarie perch (Macquaria australasica) at a similar thermal threshold (Starrs et al. 2011). Suboptimal water temperatures reduce swimming ability in a number of freshwater species in other regions (Childs and Clarkson 1996; Myrick and Cech 2000; Ward et al. 2002). The combined effects of decreased body size and impaired swimming ability under sub-optimal thermal conditions exacerbates predation risk and limits the ability of fish to find prey (Sogard 1997). Considering these compounding effects, we highlight the need to consider sub- 
lethal responses to suboptimal thermal regimes in the management of fish populations.

Mitigation of cold water pollution has been either considered or implemented in some affected regions. The success of mitigation is usually determined by estimates of mortality or by reproductive measures (Ferrari 1987; Gray et al. 2019; Hanna et al. 1999; Sherman 2000; USDI 1999). Population modelling of Murray cod downstream of Dartmouth Dam suggested that a $5-6{ }^{\circ} \mathrm{C}$ increase in water temperature from $13{ }^{\circ} \mathrm{C}$ would be necessary to diminish the effects of thermal pollution on the reproductive success of the Murray cod in the Mitta Mitta (Todd et al. 2005). A similar study determined that mitigation of reduced water temperature pollution below Hume Dam would likely see 4-6 ${ }^{\circ} \mathrm{C}$ increases downstream which was predicted to improve spawning conditions and increase female population abundance by $30-300 \%$ (Sherman et al. 2007). Although such improvements in temperature would be beneficial, our results indicate that further improvements to these temperatures would be required to diminish the effects of this cold water pollution on fish growth at early life-history stages and the associated consequences to individual fitness. Our results emphasize the value in recovering water temperatures of freshwater ecosystems to natural thermal regimes and highlight the need to consider sub-lethal responses in fish to thermal pollution in future mitigation efforts.

A strong somatic-otolith size relationship was maintained in silver perch, trout cod and golden perch when fish were exposed to suboptimal water temperatures. A number of studies have reported that slower growing individuals often have larger otoliths at a given size (Secor et al. 1989; Francis et al. 1993; Wright et al. 1990). Such decoupling of somatic and otolith growth has the potential to create biases in back-calculated estimates of fish growth histories and biochronological analyses, particularly when fish in similar geographical regions can display discrepancies in the relationships determining otolith growth (Fey 2006). For some species it is proposed that increased metabolic activity, brought on by increased water temperatures, increases the rate of accretion of material in the otolith microstructure (Mosegaard et al. 1988; Wright et al. 1990; Fey 2006). Analysis that has observed decoupling between otolith and somatic growth has generally focussed on temperatures above optimal for somatic growth; in these assessments somatic growth slowed above thermal optima whilst otolith growth continued (Mosegaard et al.
1988; Wright et al. 1990; Hoff and Fuiman 1993). A potential reason for the strong coupling between somatic and otolith growth in our study might be explained by the fact that we only assessed temperatures below and within the optimal range for the study species and therefore no metabolic driven accretion of material occurred in the otolith.

In early life history stages, ontogenetic development of otolith shape tends to shift from a circular (larval) to a more irregular or elliptical shape (adult); this has been observed in a number of species including walleye pollock (Theragra chalcogramma) (Brown et al. 2001), windowpane (Scophthalmus aquosus) (Neuman et al. 2001) and plaice (Pleuronectes platessa) (Modin et al. 1996). The otoliths of fish held at low water temperature were more circular in shape than fish of the same age held at higher temperatures. This provides further evidence for the maintenance of a strong somatic-otolith relationship in these species when exposed to suboptimal water temperatures. Given the prevalence of otolith microstructure assessment in back-calculations of fish age and growth in current fishery research (Nishimura and Yamada 1984; Radtke 1989; Cordes and Allen 1997; Karlou-Riga 2000; Buckmeier et al. 2002; Fablet and Le Josse 2005; Bermejo et al. 2007), understanding environmental conditions and processes that affect growth and development of otoliths is essential in ensuring ongoing reliability of these techniques and the applicability of their use in management of fish populations (Campana and Neilson 1985; Sponaugle 2010). With a strong somatic-otolith size relationship being maintained by silver perch, trout cod and golden perch at suboptimal water temperatures, we validate the use of otoliths in the analysis of life-history of these species in populations that have been exposed the widespread cold water pollution that persists in their native distribution.

\section{Conclusion}

Due to the importance of body size on survival, fitness, feeding ability and overall health in fish, the sub-lethal effects of temperature on growth identified in this study will likely have further significant effects on population health (Sogard 1997). Combined with the direct impacts of temperature on swimming ability, reduced thermal regimes in freshwater ecosystems have the potential to drastically alter fish communities in regulated river 
systems globally. Understanding the sub-lethal impacts of somatic and otolith growth and development experienced by freshwater fish exposed to thermal pollution is critical in the management of threatened fish populations and highlights the need for effective mitigation of sources of thermal pollution.

Acknowledgements The authors would like to pass on their sincere gratitude for the guidance and advice provided by all staff of the Narrandera Fisheries Centre and their generosity in providing use of facilities and resources, in particular Lachie Jess and Matt McLellan, as well as Daniel Wright and Osmar Luiz for assistance with statistical analysis. Financial support for this research was provided by DPI Water and DPI Fisheries, The Fisheries Scientific Committee, The Society for Freshwater Science and the Australian Wildlife Society. Ethics approval for this research was granted by the University of Technology Sydney Animal Care and Ethics Committee under permit ETH18-2580.

\section{References}

Abbink W, Garcia AB, Roques JA, Partridge GJ, Kloet K, Schneider O (2012) The effect of temperature and $\mathrm{pH}$ on the growth and physiological response of juvenile yellowtail kingfish Seriola lalandi in recirculating aquaculture systems. Aquaculture 330:130-135

Astles KL, Winstanley RK, Harris JH, Gehrke PC (2003) Experimental study of the effects of cold water pollution on native fish. NSW Fisheries Research Institute, Sydney, p 54

Barber M, Jenkins G (2001) Differential effects of food and temperature lead to decoupling of short-term otolith and somatic growth rates in juvenile King George whiting. J Fish Biol 58(5):1320-1330

Baumann H, Peck MA, Herrmann J-P (2005) Short-term decoupling of otolith and somatic growth induced by food level changes in postlarval Baltic sprat, Sprattus sprattus. Mar Freshw Res 56(5):539-547

Beitinger TL, Bennett WA, McCauley RW (2000) Temperature tolerances of north American freshwater fishes exposed to dynamic changes in temperature. Environ Biol Fish 58(3): 237-275

Bermejo S, Monegal B, Cabestany J (2007) Fish age categorization from otolith images using multi-class support vector machines. Fish Res 84(2):247-253

Brett JR (1971) Energetic responses of salmon to temperature. A study of some thermal relations in the physiology and freshwater ecology of sockeye salmon (Oncorhynchus nerkd). Am Zool 11(1):99-113

Brown A, Busby M, Mier K (2001) Walleye Pollock Theragra chalcogramma during transformation from the larval to juvenile stage: otolith and osteological development. Mar Biol 139(5):845-851

Buckmeier DL, Irwin ER, Betsill RK, Prentice JA (2002) Validity of otoliths and pectoral spines for estimating ages of channel catfish. N Am J Fish Manag 22(3):934-942
Buentello JA, Gatlin DM III, Neill WH (2000) Effects of water temperature and dissolved oxygen on daily feed consumption, feed utilization and growth of channel catfish (Ictalurus punctatus). Aquaculture 182(3-4):339-352

Burton C (2000) Assessment of the water temperature regime of the Macquarie River, central west, New South Wales. NSW Department of Land and Water Conservation, Dubbo

Campana SE (1999) Chemistry and composition of fish otoliths: pathways, mechanisms and applications. Mar Ecol Prog Ser 188:263-297

Campana SE, Neilson JD (1985) Microstructure of fish otoliths. Can J Fish Aquat Sci 42(5):1014-1032

Childs MR, Clarkson RW (1996) Temperature effects on swimming performance of larval and juvenile Colorado squawfish: implications for survival and species recovery. Trans Am Fish Soc 125(6):940-947

Clarkson RW, Childs MR (2000) Temperature effects of hypolimnial-release dams on early life stages of Colorado River basin big-river fishes. Copeia 2:402-412

Comte L, Olden JD (2017) Evolutionary and environmental determinants of freshwater fish thermal tolerance and plasticity. Glob Chang Biol 23(2):728-736

Cordes JF, Allen LG (1997) Estimates of age, growth, and settlement from otoliths of young-of-the-year kelp bass (Paralabrax clathratus). Bull South Calif Acad Sci 96:43-60

Domenici P (2001) The scaling of locomotor performance in predator-prey encounters: from fish to killer whales. Comp Biochem Physiol A Mol Integr Physiol 131(1):169-182

Domenici P, Blake R (1997) The kinematics and performance of fish fast-start swimming. J Exp Biol 200(8):1165-1178

Fablet R, Le Josse N (2005) Automated fish age estimation from otolith images using statistical learning. Fish Res 72(2-3): 279-290

Fausch KD, White RJ (1986) Competition among juveniles of coho salmon, brook trout, and brown trout in a laboratory stream, and implications for Great Lakes tributaries. Trans Am Fish Soc 115(3):363-381

Fernández-Montero A, Caballero MJ, Torrecillas S, Tuset VM, Lombarte A, Ginés RR, Izquierdo M, Robaina L, Montero D (2018) Effect of temperature on growth performance of greater amberjack (Seriola dumerili Risso 1810) juveniles. Aquac Res 49(2):908-918

Ferrari R (1987) Colorado River water temperature modeling below Glen Canyon Dam. Glen Canyon Environmental Studies Report GCES/13/87. Durango Projects Office, Upper Colorado Region, US Bureau of Reclamation

Fey D (2006) The effect of temperature and somatic growth on otolith growth: the discrepancy between two clupeid species from a similar environment. J Fish Biol 69(3):794-806

Fisher R, Leis JM, Clark DL, Wilson SK (2005) Critical swimming speeds of late-stage coral reef fish larvae: variation within species, among species and between locations. Mar Biol 147(5):1201-1212

Folkvord A, Johannessen A, Moksness E (2004) Temperaturedependent otolith growth in Norwegian spring-spawning herring (Clupea harengus L.) larvae. Sarsia N Atl Mar Sci 89(5):297-310

Francis MP, Williams MW, Pryce AC, Scott SG (1993) Uncoupling of otolith and somatic growth in Pagrus auratus (Sparidae). Fish Bull 91(1):159 
Gagliano M, McCormick MI (2004) Feeding history influences otolith shape in tropical fish. Mar Ecol Prog Ser 278:291-296

Gauldie R, Nelson D (1990) Otolith growth in fishes. Comp Biochem Physiol A Physiol 97(2):119-135

Gehrke PC (1988) Feeding energetics and angling catches of spangled perch, Leiopotherapon unicolor (Günther 1859), (Percoidei: Teraponidae). Mar Freshw Res 39(4):569-577

Gray R, Jones HA, Hitchcock JN, Hardwick L, Pepper D, Lugg A, Seymour JR, Mitrovic SM (2019) Mitigation of cold-water thermal pollution downstream of a large dam with the use of a novel thermal curtain. River Res Appl 35:855-866

Green BS, Fisher R (2004) Temperature influences swimming speed, growth and larval duration in coral reef fish larvae. $\mathrm{J}$ Exp Mar Biol Ecol 299(1):115-132

Gunderson AR, Stillman JH (2015) Plasticity in thermal tolerance has limited potential to buffer ectotherms from global warming. Proc R Soc B Biol Sci 282(1808):20150401

Hanna RB, Saito L, Bartholow JM, Sandelin J (1999) Results of simulated temperature control device operations on inreservoir and discharge water temperatures using CEQUAL-W2. Lake Reserv Manag 15(2):87-102

Hoff GR, Fuiman LA (1993) Morphometry and composition of red drum otoliths: changes associated with temperature, somatic growth rate, and age. Comp Biochem Physiol A Physiol 106(2):209-219

Imsland A, Sunde L, Folkvord A, Stefansson S (1996) The interaction of temperature and fish size on growth of juvenile turbot. J Fish Biol 49(5):926-940

Jobling M (1983) Growth studies with fish-overcoming the problems of size variation. J Fish Biol 22(2):153-157

Jobling M (1995) Fish bioenergetics. Oceanogr Lit Rev 9(42):785

Jobling M (ed) (1997) Temperature and growth: modulation of growth rate via temperature change. Cambridge University Press, Cambridge

Johnson TB, Evans DO (1990) Size-dependent winter mortality of young-of-the-year white perch: climate warming and invasion of the Laurentian Great Lakes. Trans Am Fish Soc 119(2):301-313

Johnson TB, Evans DO (1996) Temperature constraints on overwinter survival of age- 0 white perch. Trans Am Fish Soc 125(3):466-471

Jonassen T, Imsland A, Stefansson S (1999) The interaction of temperature and fish size on growth of juvenile halibut. J Fish Biol 54(3):556-572

Jones CM (1992) Development and application of the otolith increment technique Otolith microstructure examination and analysis. Canad Spec Publ Fish Aquat Sci 117:1-11

Karlou-Riga C (2000) Otolith morphology and age and growth of Trachurus mediterraneus (Steindachner) in the eastern Mediterranean. Fish Res 46(1-3):69-82

Kitchell JF, Stewart DJ, Weininger D (1977) Applications of a bioenergetics model to yellow perch (Perca flavescens) and walleye (Stizostedion vitreum vitreum). J Fish Board Can 34(10):1922-1935

Koehn J (2001) Ecological impacts of cold water releases on fish and ecosystem processes. In: Thermal Pollution of the Murray-Darling Waterways: Workshop Held at Lake Hume:18-19. (ed. B. Phillips). Inland Rivers Networkand World Wide Fund for Nature Australia, Sydney
Libungan L, Pálsson S (2015a) ShapeR: collection and analysis of Otolith shape data, $\mathrm{R}$ package version 0.1-5. Available at http://github.com/lisalibungan/shapeR

Libungan LA, Pálsson S (2015b) ShapeR: an R package to study otolith shape variation among fish populations. PLoS One 10(3):e0121102

Lugg A, Copeland C (2014) Review of cold water pollution in the Murray-Darling basin and the impacts on fish communities. Ecol Manag Restor 15(1):71-79. https://doi.org/10.1111 /emr.12074

Lyon J, Ryan T, Scroggie M (2008) Effects of temperature on the fast-start swimming performance of an Australian freshwater fish. Ecol Freshw Fish 17(1):184-188

Michie LE, Hitchcock JN, Thiem JD, Boys CA, Mitrovic SM (2020) The effect of varied dam release mechanisms and storage volume on downstream river thermal regimes. Limnologica 81:125760

Modin J, Fagerholm B, Gunnarsson B, Pihl L (1996) Changes in otolith microstructure at metamorphosis of plaice, Pleuronectes platessa L. ICES J Mar Sci 53(4):745-748

Morita K, Fukuwaka M, Tanimata N, Yamamura O (2010) Sizedependent thermal preferences in a pelagic fish. Oikos 119(8):1265-1272

Morrison CM, Kunegel-Lion M, Gallagher CP, Wastle RJ, Lea EV, Loewen TN, Reist JD, Howland KL, Tierney KB (2019) Decoupling of otolith and somatic growth during anadromous migration in a northern salmonid. Can J Fish Aquat Sci 76(11):1940-1953

Morrongiello JR, Thresher RE, Smith DC (2012) Aquatic biochronologies and climate change. Nat Clim Chang 2(12):849-857

Mosegaard H, Svedäng H, Taberman K (1988) Uncoupling of somatic and otolith growth rates in Arctic char (Salvelinus alpinus) as an effect of differences in temperature response. Can J Fish Aquat Sci 45(9):1514-1524

Myrick CA, Cech JJ (2000) Swimming performances of four California stream fishes: temperature effects. Environ Biol Fish 58(3):289-295

Neuman M, Witting D, Able K (2001) Relationships between otolith microstructure, otolith growth, somatic growth and ontogenetic transitions in two cohorts of windowpane. J Fish Biol 58(4):967-984

Nishimura A, Yamada J (1984) Age and growth of larval and juvenile walleye Pollock, Theragra chalcogramma (Pallas), as determined by otolith daily growth increments. J Exp Mar Biol Ecol 82(2-3):191-205

NSW-CWPIG (2012) Cold water pollution strategy in NSW report on the implementation of stage one. Published by NSW Department of Primary Industries, Water

Ojanguren A, Brana F (2003) Effects of size and morphology on swimming performance in juvenile brown trout (Salmo trutta L.). Ecol Freshw Fish 12(4):241-246

Oksanen J et al (2016) Vegan: community ecology package. R package version 2. 4-3. Available at http://CRAN.R-project. org/package= $=$ egan

Pannella G (1971) Fish otoliths: daily growth layers and periodical patterns. Science 173(4002):1124-1127

Pérez-Casanova JC, Lall SP, Gamperl AK (2009) Effect of feed composition and temperature on food consumption, growth and gastric evacuation of juvenile Atlantic cod (Gadus 
morhua L.) and haddock (Melanogrammus aeglefinus L.). Aquaculture 294(3-4):228-235

R Core Team (2019) R: a language and environment for statistical computing. R Foundation for Statistical Computing, Vienna

Radtke RL (1989) Larval fish age, growth, and body shrinkage: information available from otoliths. Can J Fish Aquat Sci 46(11):1884-1894

Rice JA, Crowder LB, Holey ME (1987) Exploration of the mechanisms regulating larval survival in Lake-Michigan bloater; a recruitment analysis based on characteristics of individual larvae. Trans Am Fish Soc 116(5):703-718. https://doi.org/10.1577/1548-8659(1987)116<703 :eomrls $>2.0 . \mathrm{co} ; 2$

Roessig JM, Woodley CM, Cech JJ, Hansen LJ (2004) Effects of global climate change on marine and estuarine fishes and fisheries. Rev Fish Biol Fish 14(2):251-275

Ryan T, Lennie, R, Lyon J, O'Brien T (2003) Thermal rehabilitation of the southern Murray-Darling basin. Final Report to Agriculture, Forestry, Fisheries Australia

Schindelin J, Arganda-Carreras I, Frise E, Kaynig V, Longair M, Pietzsch T, Preibisch S, Rueden C, Saalfeld S, Schmid B, Tinevez JY, White DJ, Hartenstein V, Eliceiri K, Tomancak P, Cardona A (2012) Fiji: an open-source platform for biological-image analysis. Nat Methods 9(7):676-682

Secor DH, Dean JM, Baldevarona RB (1989) Comparison of otolith growth and somatic growth in larval and juvenile fishes based on otolith length/fish length relationships. Rapp Pv Réun Cons Int Explor Mer 191:431-438

Sherman B (2000) Scoping options for mitigating cold water discharges from dams. CSIRO Land and Water, Canberra

Sherman B, Todd CR, Koehn JD, Ryan T (2007) Modelling the impact and potential mitigation of cold water pollution on Murray cod populations downstream of Hume dam, Australia. River Res Appl 23(4):377-389. https://doi. org/10.1002/rra.994

Sogard SM (1997) Size-selective mortality in the juvenile stage of teleost fishes: a review. Bull Mar Sci 60(3):1129-1157

Sponaugle S (2010) Otolith microstructure reveals ecological and oceanographic processes important to ecosystem-based management. Environ Biol Fish 89(3-4):221-238

Starrs D, Ebner B, Lintermans M, Fulton C (2011) Using sprint swimming performance to predict upstream passage of the endangered Macquarie perch in a highly regulated river. Fish Manag Ecol 18(5):360-374

Starrs D, Ebner BC, Fulton C (2013) Can backcalculation models unravel complex larval growth histories in a tropical freshwater fish? J Fish Biol 83(1):96-110
Todd CR, Ryan T, Nicol SJ, Bearlin AR (2005) The impact of cold water releases on the critical period of post-spawning survival and its implications for Murray cod (Maccullochella peelii peelii): a case study of the Mitta Mitta River, southeastern Australia. River Res Appl 21(9):1035-1052. https://doi. org $/ 10.1002 /$ rra. 873

Tonkin Z, King AJ, Ramsey D (2008a) Otolith increment width responses of juvenile Australian smelt Retropinna semoni to sudden changes in food levels: the importance of feeding history. J Fish Biol 73(4):853-860

Tonkin Z, King AJ, Robertson A (2008b) Validation of daily increment formation and the effects of different temperatures and feeding regimes on short-term otolith growth in Australian smelt Retropinna semoni. Ecol Freshw Fish 17(2):312-317

USDI (1999) Glen canyon dam modifications to control downstream temperatures: plan and draft environmental assessment. USDI, Bureau of Reclamation, Upper Colorado Region, Salt Lake City

Van Vliet MT et al (2013) Global river discharge and water temperature under climate change. Glob Environ Chang 23(2):450-464

Verones F, Hanafiah MM, Pfister S, Huijbregts MA, Pelletier GJ, Koehler A (2010) Characterization factors for thermal pollution in freshwater aquatic environments. Environ Sci Technol 44(24):9364-9369

Videler J, Wardle C (1991) Fish swimming stride by stride: speed limits and endurance. Rev Fish Biol Fish 1(1):23-40

Ward DL, Eugene Maughan O, Bonar SA, Matter WJ (2002) Effects of temperature, fish length, and exercise on swimming performance of age-0 flannelmouth sucker. Trans Am Fish Soc 131(3):492-497

Weber M, Rinke K, Hipsey MR, Boehrer B (2017) Optimizing withdrawal from drinking water reservoirs to reduce downstream temperature pollution and reservoir hypoxia. J Environ Manag 197:96-105. https://doi.org/10.1016/j. jenvman.2017.03.020

Wolter C, Arlinghaus R (2003) Navigation impacts on freshwater fish assemblages: the ecological relevance of swimming performance. Rev Fish Biol Fish 13(1):63-89

Wright P, Metcalfe N, Thorpe J (1990) Otolith and somatic growth rates in Atlantic salmon parr, Salmo salar L: evidence against coupling. J Fish Biol 36(2):241-249

Publisher's note Springer Nature remains neutral with regard to jurisdictional claims in published maps and institutional affiliations. 